\title{
Structural control of scarps in the Rembrandt region of
}

\section{Mercury}

a Departamento de Geodinámica, Facultad de Ciencias Geológicas, Universidad

${ }^{\mathrm{b}}$ Escuela Técnica Superior de Ingenieros en Topografía, Geodesia y Cartografía,

11 Universidad Politécnica de Madrid, Carretera de Valencia, km 7.5, 28031 Madrid, Spain

${ }^{\mathrm{c}}$ Department of Hydrology and Water Resources, University of Arizona, Tucson 85721, AZ, USA.

$14{ }^{\mathrm{d}}$ Departamento de Geodinámica y Paleontología, Universidad de Huelva, Campus de El Carmen, 21071 Huelva, Spain

16

17 


\section{Abstract}

2 Lobate scarps, thought to be the surface expression of large thrust faults, are the

3 most spectacular contractional tectonic features visible on Mercury. Most lobate scarps

4 follow a general and relatively simple pattern, with a roughly arcuate or linear form in plan

5 view, and an asymmetric cross section characterized by a steeply rising scarp face and a

6 gently declining back scarp. In this work, we study two peculiar and complex scarps in the

7 Rembrandt region of Mercury through MESSENGER imagery. On the one hand, the

8 formation of these scarps resulted in the deformation of features such as impact craters,

9 fractures, extensional faults, and volcanic plains, while on the other hand, the deformed

10 features partly influenced the formation of the scarps. Evidence for structural control on the

11 formation of the scarps includes their orientation, segmentation, bifurcation, change in

12 structural trend and dip orientation, and transition into high-relief ridges or wrinkle ridge

13 morphologies in some cases. Thus, these two lobate scarps provide examples of complex

14 geological relations among other features, expanding the recognized richness of mercurian

15 geology. Also, the southern scarp records a complex history of contraction, suggesting that

16 the development of some mercurian lobate scarps may be more complex than usually

17 thought.

18 Key words: Mercury; Tectonics; Terrestrial planets

\section{Introduction}

21 Lobate scarps are the most spectacular contractional tectonic features visible on the

22 surface of Mercury (e.g., Strom et al., 1975; Dzurisin, 1978; Watters et al., 2001, 2009a;

23 Watters and Nimmo, 2010). Lobate scarps, which are thought to be the surface expression 
1 of large thrust faults resulting from contraction due to the cooling of the planet (e.g., Strom

2 et al., 1975), deform the crust at depths ranging from 30 to $40 \mathrm{~km}$ (Watters et al., 2001;

3 Egea-González et al., 2012). Their formation probably occurred during an important part of

4 the mercurian geological history, with some being relatively young features (Watters et al.,

5 2009a; Watters and Nimmo, 2010).

6 Most lobate scarps follow a general and relatively simple pattern, showing an

7 approximately arcuate to linear form, and an asymmetric cross section characterized by a

8 steeply rising scarp face and a gently declining back scarp (Watters et al., 1998, 2001).

9 Other contractional features of Mercury are high-relief ridges and wrinkle ridges (for a

10 review of the tectonics of Mercury see Watters and Nimmo, 2010); high-relief ridges are

11 usually scarce, symmetric in cross section, and can transition into lobate scarps, suggesting

12 a genetic relation, whereas wrinkle ridges are sinuous, morphologically complex, and

13 generally located on volcanic plains.

14 Lobate-scarp development and plan-view morphology could have been influenced

15 by pre-existing impact basins, which would have affected the mechanical behavior of the

16 mercurian crust (Spudis and Guest, 1988). This is suggested by trends of some lobate scarp

17 segments which parallel the rims of impact craters (e.g., Watters et al., 2001). On the other

18 hand, structural control of lobate scarps by pre-existing tectonic structures has not yet been

19 detailed in the literature on Mercury.

20 In this work, we study two peculiar and complex scarps imaged by the

21 MESSENGER spacecraft in the Rembrandt region of Mercury (see Figure 1). These scarps

22 show an amazing variety of evidence for structural control by pre-existing landforms,

23 including impact craters, fractures, extensional faults, and volcanic plains. The evidence 
1 includes orientation, segmentation, bifurcation, abrupt change in structural trend, changes

2 of dip orientation, and transition into high-relief and wrinkle ridge morphologies at or near

3 impact crater margins and/or tectonic structures such as faults. Thus, these two scarps

4 provide examples of tectonic complexity previously not reported for Mercury.

\section{2. The Rembrandt region}

MESSENGER first imaged the Rembrandt region during its second and third flybys

8 around Mercury (Figure 1). This region includes cratered terrains and intercrater plains. A

9 complex geological history, including tectonism (contractional and extensional) and

10 volcanism has been previously reported for the Rembrandt crater (Watters et al., 2009b),

11 but detailed geological analysis has not been extended to the surroundings.

12 Figure 1 shows the two scarps studied in this work. Both scarps have a roughly

13 ENE-WSW trend. The eastern part of the northern scarp (hereafter referred to as the RS1

14 scarp) deforms the heavily cratered terrain and the western margin of the Rembrandt crater,

15 whereas its western part deforms intercrater plains. The southern scarp (hereafter referred

16 to as the RS2 scarp) deforms the intercrater plains located to the southwest of the

17 Rembrandt crater. In the next section, we describe both lobate scarps and their spatial

18 association (and interaction) with other geological features.

\section{3. The RS1 and RS2 scarps}

21 The morphology of RS1 in plan view is relatively simple, though there appears to be

22 fault segments. The east end of RS1 has a northeasterly trend, a prominent southeast-facing

23 scarp, and disrupts and thrusts the Rembrandt impact basin as clearly visible on a shortened 
1 and thrusted small crater inside this basin (Watters et al., 2009b). This feature was

2 interpreted by Watters et al. (2009b) as lobate scarp, but there is also a northwest-facing

3 scarp associated to RS1, somewhat approximating their morphology to that of high relief

4 ridges (see Dzurisin, 1978; Watters et al., 2009a). However, the northwest-facing scarp is

5 less prominent, as evidenced through both preliminary stereo topographic models based on

6 MESSENGER imagery (Preusker et al., 2011) and comparison with illumination and

7 shadowing of both small ridges visible on the plains in the Rembrandt basin and nearby

8 impact craters. Thus, whereas the southeast facing-scarp must be related to the main

9 underlying thrust fault, the northwest-facing scarp can be interpreted as a secondary

10 backthrust fault.

11 Coinciding with a change to a more east-west trend of RS1 and a structural

12 discontinuity as it transects the Rembrandt rim to the west (Figure 2), the morphology in

13 plan view becomes more complex. The change coincides with a small impact crater just

14 inside the eastern rim of the Rembrandt basin (crater A of Figure 2). Inside crater A, the

15 geometry of RS1 is obscured by the tectonic complexity of the Rembrandt rim, including a

16 small and N-S oriented scarp (Figure 2) crossing crater A. The south-facing scarp of RS1

17 inside this small crater appears to be located close to the inner crater rim, and for this

18 reason it is less visible than the north-facing scarp associated to the backthrust in the east

19 part of RS1. Alternatively, the north-facing scarp inside crater A could be a fault segment

20 boundary that separates individual thrust faults outside this crater.

21 West of Rembrandt rim, RS1 is nearly rectilinear, and has an appearance more

22 similar to that observed in high-relief ridges (or linear ridges in the terminology of Dzurisin

23 (1978)), although it is also reminiscent of some relatively linear wrinkle ridges on the 
1 martian surface (see Watters, 1993; Mueller and Golombek, 2004). Indeed, using

2 MESSENGER image data, there are distinct north- and south-facing scarps which bound an

3 elevated structure (i.e., an elongated scarp-bounded mesa). The western part of RS1

4 deforms both intercrater and heavily cratered plains materials (P12 and Pl1 of Figure 2,

5 respectively). Although the scarp-bounded mesa is similarly wide on both terrains, it is

6 more wrinkle ridge-like on the intercrater plains materials (see for example the crenulations

7 on RS1 just east of crater B of Figure 2). The putative volcanic materials may provide a

8 resistant layer overlying weak and brecciated and/or layered materials, which could favor a

9 wrinkle ridge-like structure when thrust faults deform these materials (a wrinkle ridges is

10 considered to be formed when a thrust fault, which remains blind, deforms near-surface

11 layered materials; e.g., Schultz, 2000). In fact, wrinkle ridges are observable on mercurian

12 (e.g., Caloris Planitia; Watters and Nimmo, 2010), venusian (Watters, 1988), lunar

13 (Watters, 2010), and martian (e.g., Watters, 1993; Mueller and Golombek, 2004) volcanic

14 plains. On the plains close to the west end of RS1, this scarp disrupts another impact crater

15 (crater B, Figure 2), although in this case the trajectory of the scarp is modestly affected by 16 the crater.

17 Much of the trace of the southern scarp, RS2, is roughly parallel to that of RS1,

18 including a somewhat similar northeasterly change in trend along its northeastern part.

19 However, in certain aspects, RS2 is more complex than RS1 (Figure 2). RS2 starts inside

20 the Rembrandt basin as wrinkle ridge(s) following a roughly N-S trace. Out of the

21 Rembrandt basin RS2 progressively trends into a W-SW orientation, maintaining standard

22 lobate scarp morphology, although as a low-relief feature (see also preliminary stereo

23 topographic models of the eastern part of RS2 in Preusker et al., 2011) with a south-facing 
1 scarp.

Otherwise, the RS2 scarp is constituted by a complex system of structures in the

3 intercrater plains just east of a deformed impact crater (crater $\mathrm{C}$ of Figure 2), including a

4 northeastern branch bifurcation of RS2 (see Figures 2, where this feature is marked as

$5 \mathrm{RS} 2 \mathrm{nb}$, and 3). Also, there is a nearly linear narrow trough-like feature (labeled $\mathrm{T}$ in

6 Figures 2 and 3) cutting the main scarp. The northeastern branch of RS2 reaches trough T

7 near $70^{\circ} \mathrm{E}$, and then follows, and even obscures, the trace of the northern part of this

8 feature. Trough T therefore postdates the main development of RS2, but the north branch of

9 RS2 postdates the trough, suggesting a complex geologic history for this lobate scarp. The

10 north branch of RS2 was formed or reactivated subsequently to trough T formation; the

11 trough, or more probably the associated weakness zone (since that the trough is a relatively

12 minor feature), would have contributed to control the morphology of the northern branch of

13 RS2. To the south of this zone, another lobate scarp, which has also been affected by the

14 trough T, could have been partly thrusted by RS2 (see Figure 3); in fact, this area south of

$15 \mathrm{RS} 2$ is tectonically complex, with several low scarps, oblique to RS2, whose relation with

16 this scarp remains unclear.

17 Inside the crater C (Figures 2 and 3), RS2 has definite north- and south-facing

18 scarps. Also, RS2 is crossed inside crater C by a narrow trough-like landform; RS2 seems

19 slightly offset by this narrow feature, but we interpret this as an apparent impression, since

20 no other features are similarly offset by the trough-like landform. West of crater C, RS2 is a

21 single structure with a clearly north-facing scarp, suggesting an inversion of fault dip

22 orientation; this north-facing scarp orientation of the western portion of RS2 is clearly

23 evident in Figure 3, confirming the change of dip fault orientation. A possible interpretation 
1 of the structure of RS2 is shown in Figure 3b.

\section{4. Discussion and conclusions}

4 The two large lobate scarps in the Rembrandt region of this study show complex

5 geological relations with other features, which expands the recorded richness of mercurian 6 geology.

The RS1 scarp records lateral changes in morphology from an appearance similar to

8 that of typical lobate scarps inside the Rembrandt basin (although including a probably

9 backthrust scarp smaller than the main one) to a high-relief ridge appearance outside the

10 crater, although somewhat resembling a wrinkle ridge-like morphology in the intercrater

11 plains. In turn, RS2 transitions from wrinkle ridges in the plains inside the Rembrandt basin

12 to lobate scarp outside the basin. Transitions from lobate scarps to high-relief ridges are

13 known on Mercury (Watters et al., 2001; Watters and Nimmo, 2010): both types of features

14 might be related to large reverse faults, which would have a higher dipping angle in the

15 later case (Watters and Nimmo, 2010). Thus, the change in morphology of RS1 occurring

16 in the Rembrandt basin rim could therefore be related to variations in fault dip angles inside

17 and outside the basin. In this sense, Ferrari et al. (2011) have recently suggested that the

18 presence of the Rembrandt basin might have affected the development of this scarp, maybe

19 due to an inhomogeneous crustal layering.

20 Similarly, a transition from lobate scarps to wrinkle ridges has been reported for

21 some lunar and martian structures (Lucchitta, 1976; Watters, 1993; Mangold et al., 1998;

22 Anguita et al., 2006, Watters and Johnson, 2010), also associated with similar change in

23 surface geology from cratered terrains to plains materials. This could be explained by more 
1 competent volcanic materials overlying unconsolidated (i.e., brecciated and/or layered)

2 impact crater infill deposits, which would favor winkle ridge formation. Also, there is

3 distinct structural control, as the eastern part of the RS1 scarp, near the western margin of

4 Rembrandt basin (near impact crater A), abruptly changes trend and appears to be

5 segmented, eventually transitioning into a narrow high-relief ridge.

6 Thus, lateral changes in the general morphology of RS1 and RS2 can be well

7 correlated with local structural control, and the complexity of these changes is direct

8 function of the complexity of the local geology.

9 Moreover, the RS2 scarp has experienced a complex and long history of contraction.

10 A first phase of compression originated the main scarp and thrusted other pre-existing

11 lobate scarps. Subsequently, two trough-like landforms cut the main scarp. Finally, new

12 compression formed or reactivated a north branch of RS2, possibly following the structural

13 control of the weakness zone associated to the trough-like feature $\mathrm{T}$. This interpretation

14 may be overly simplified, but our work confirms previous works suggesting that the

15 development of at least some mercurian lobate scarps may be more complex than usually

16 thought (Rothery and Massironi, 2010; Ferrari et al., 2011). The total amount of radius

17 reduction deduced from shortening on lobate scars is 0.6-0.9 km (Watters et al., 2009),

18 although this estimate is considered to be a lower limit due to lighting conditions. The

19 actual global contraction could be even higher if thrusting of pre-existing lobate scarps is a

20 common phenomenon. Moreover, reactivated faults might complicate the estimates of

21 global contraction. Thus, the global tectonic evolution of Mercury could be more complex

22 than a simple cooling-driven contraction.

23 High resolution images (and stereo topographic models that could potentially be 
1 produced from these images) obtained during the orbital phase of MESSENGER (with

2 resolutions of $\sim 200-300$ m per pixel at the Rembrandt region) will serve to improve the

3 tectonic description of the scarps analyzed in this study, as well as the derived geological

4 history. For example, these images should help to determine the level of structural control

5 on scarps development and appearance, confirm the wrinkle ridge-like characteristics of

6 RS1 on intercrater plains materials, or determine the expression and significance of trough

7 T.

8 The analysis of individual lobate scarps is useful to improve our knowledge of local

9 tectonic and crustal mechanical properties (see also Rothery and Massironi, 2010), but we

10 have shown that it also potentially has implications for the global geological history of

11 Mercury.

12

13 Acknowledgements

14 We thank the comments and suggestion from an anonymous reviewer. JR work was

15 supported by a contract Ramón y Cajal co-financed from the Ministerio de Ciencia e

16 Innovación of Spain and the European Social Fund.

17

18

19

20

21

22

23 


\section{References}

2 Anguita, F, Fernández, C., Cordero, G., Carrasquilla, S., Anguita, J., Núñez, A., Rodríguez, S., García, J., 2006. Evidences for a Noachian-Hesperian orogeny in Mars. Icarus $185,331-357$.

Dzurisin, D., 1978. The tectonic and volcanic history of Mercury as inferred from studies of scarps, ridges, throughs and other lineaments. J. Geophys. Res. 83, 4883-4906.

Egea-González, I., Ruiz, J., Fernández, C., Williams, J.-P., Márquez, A., Lara, L.M., 2012. Depth of thrust faulting and ancient heat flows in the Kuiper region of Mercury from lobate scarp topography. Planet. Spa. Sci. 60, 193-198.

Ferrari, S., Massironi, M., Rothery, D.A., Cremonese, G., 2011. Beagle Rupes and Rembrandt scarp: a comparison on Mercury surface. EPSC Abstracts 6, EPSCDPS2011-963-1.

Lucchitta, B.K., 1976. Mare ridges and related highland scarps-Results of vertical tectonism. Geochim. Cosmochim. Acta 3 (suppl.) 2761-2782.

Mangold, N., Allemand, P., Thomas, P.G., 1998. Wrinkle ridges of Mars: structural analysis and evidence for shallow deformation controlled by ice-rich décollements. Planet. Space Sci. 46, 345-356.

Mueller, K., Golombek, M., 2004. Compressional structures on Mars. Annu. Rev. Earth Planet Sci. 32, 435-464.

Preusker, F., Oberst, J., Head, J.W., Watters, T.R., Robinson, M.S., Zuber, M.T., Solomon, S.C., 2011. Stereo topographic models after three MESSENGER flybys. Planet. Spa. Sci. 59, 1910-1917.

Rothery, D.A., Massironi, M., 2010. Beagle Rupes - evidence for a basal decollement of 
regional extent in Mercury's lithosphere. Icarus, 209, 256-261.

2 Schultz, R.A., 2000. Localization of bedding plane slip and backthrust faults above blind faults: keys to wrinkle ridge structure. J. Geophys. Res. 105, 12,035-12,052.

4 Spudis, P.D., Guest, J.E., 1988. Stratigraphy and geologic history of Mercury. In: Vilas, F., Chapman, C.R., Matthews, M.S. (Eds.), Mercury. Univ. Arizona Press, Tucson, pp 118-164.

7 Strom, R. G., Trask, N. J., Guest, J. E., 1975. Tectonism and volcanism on Mercury. J. Geophys. Res. 80, 2478-2507.

9 Watters, T.R., 1988. Wrinkle ridge assemblages on the terrestrial planets. J. Geophys. Res. $93,10,236-10,254$.

11 Watters, T.R., 1993. Compressional tectonism on Mars. J. Geophys. Res. 98, 17,049$17,060$.

Watters, T.R., Johnson, C.L., 2010. Lunar tectonics. In: Watters, T.R., Schultz, R.A. (Eds.), Planetary Tectonics. Cambridge University Press, Cambridge. pp. 121-182. (Eds.), Planetary Tectonics. Cambridge Univ. Press. Cambridge, pp 15-80.

Watters, T.R., Robinson, M.S., Cook, A.C., 1998. Topography of lobate scarps on Mercury: new constraints on the planet's contraction. Geology 26, 991-994.

Watters, T.R., Cook, A.C., Robinson, M.S., 2001. Large-scale lobate scarps in the southern hemisphere of Mercury. Planet. Spa. Sci. 49, 1523-1530.

Watters, T.R., Schultz, R.A., Robinson, M.S., Cook, A.C., 2002. The mechanical and thermal structure of Mercury's early lithosphere. Geophys. Res. Lett. 29, 10.1029/2001GL014308. 
1 Watters, T.R., Solomon, S.C., Robinson, M.S., Head, J.W., André, S.L., Hauck, S.A., Murchie, S.L., 2009a. The tectonics of Mercury: The view after MESSENGER's first flyby. Earth and Planet. Sci. Lett. 285, 283-296.

4 Watters, T.R., Head, J.W., Solomon, S.C., Robinson, M.S., Chapman, C.R., Denevi, B.W., Fasset, C.I., Murchie, S.L., Strom, R.G., 2009b. Evolution of the Rembrandt impact basin on Mercury. Science 324, 618-621.

Watters, T.R., et al., 2010. Evidence of recent thrust faulting on the Moon revealed by the Lunar Reconnaissance Orbiter Camera. Science 329, 936-940. 


\section{Figure caption}

Figure 1. A MESSENGER-based mosaic with a resolution of 500 meters/pixel

$4 \quad$ ( 85.17 pixels/degree) showing the northern and southern lobate scarps analyzed in this

5 investigation (RS1 and RS2, respectively), which are interpreted as thrust faults. Prepared

6 with data obtained from the US Geological Survey web site (available on-line at

7 http://astrogeology.usgs.gov/products/Mercury-Messenger-Global-Mosaic).

Figure 2. The same MESSENGER-based mosaic of Figure 1 detailing northern and

9 southern scarps of this investigation (RS1 and RS2, respectively), interpreted to mark thrust

10 faults, including other scarps (red lines), Rembrandt impact crater rim (blue lines),

11 Rembrandt basin and a north-trending basin, both of which contain intercrater plains

12 materials (P12) delineated by approximate geologic contacts (white lines), heavily cratered

13 highland materials (P11), narrow ridges often wrinkle-ridge-like (pink lines), deformed

14 impact craters of special interest as detailed in the text (craters A-D), trough-like landforms

15 (tan lines), interpreted to be either extension features such as normal faults or lines of

16 coalesced secondary craters associated with the Rembrandt impact event. RS2nb is a

17 northeastern branch of RS2, and T is a narrow trough-like feature crossing the RS2 scarp;

18 both features are discussed in the main text. Both RS1 and RS2 clearly show structural

19 control in several places.

20 Figure 3. a) MESSENGER image showing RS2 in the area around crater C.

21 b) The same MESSENGER image marking scarps (red lines) and a trough-like feature

22 (labeled T), which crosses RS2. 
Click here to download high resolution image

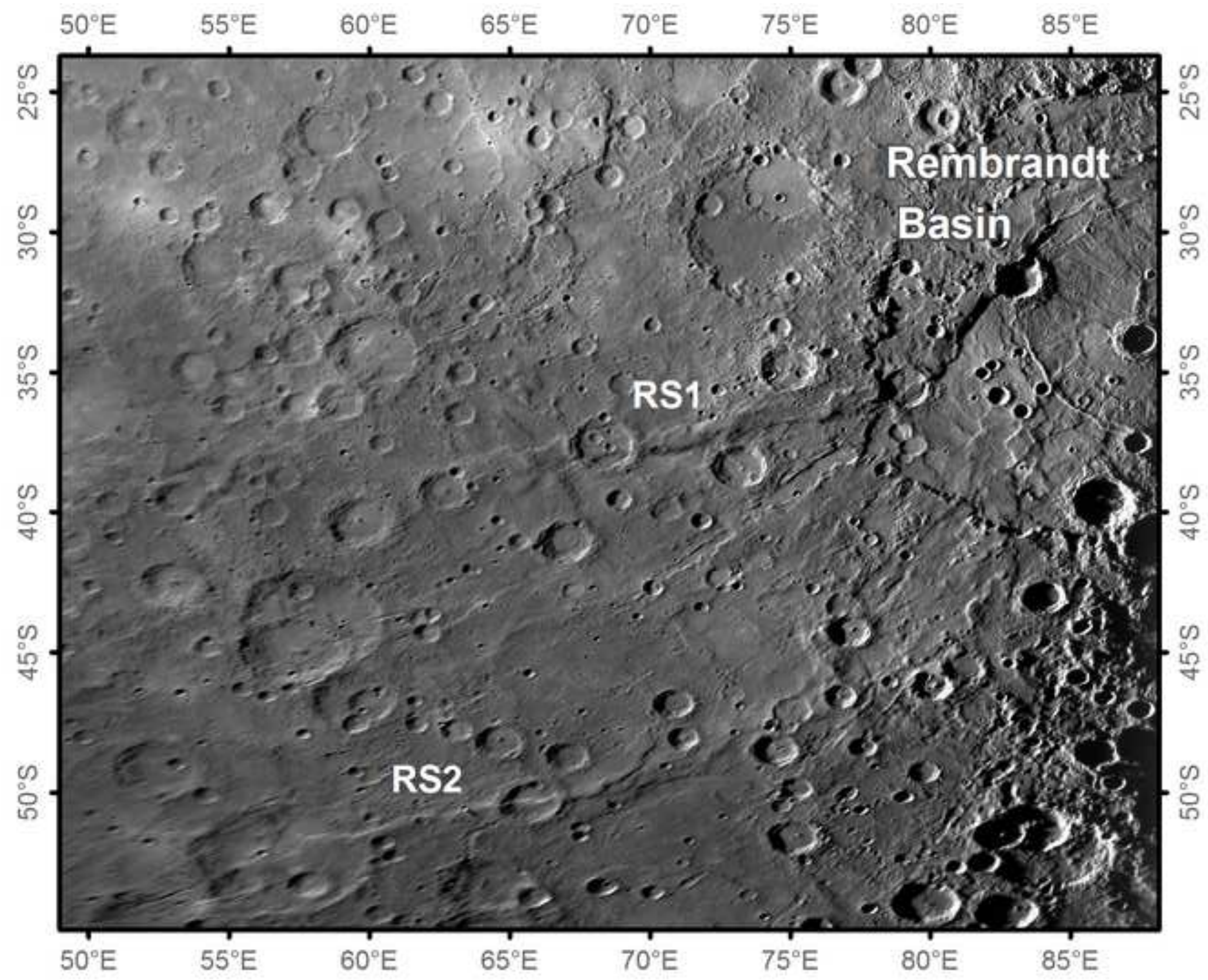


Click here to download high resolution image

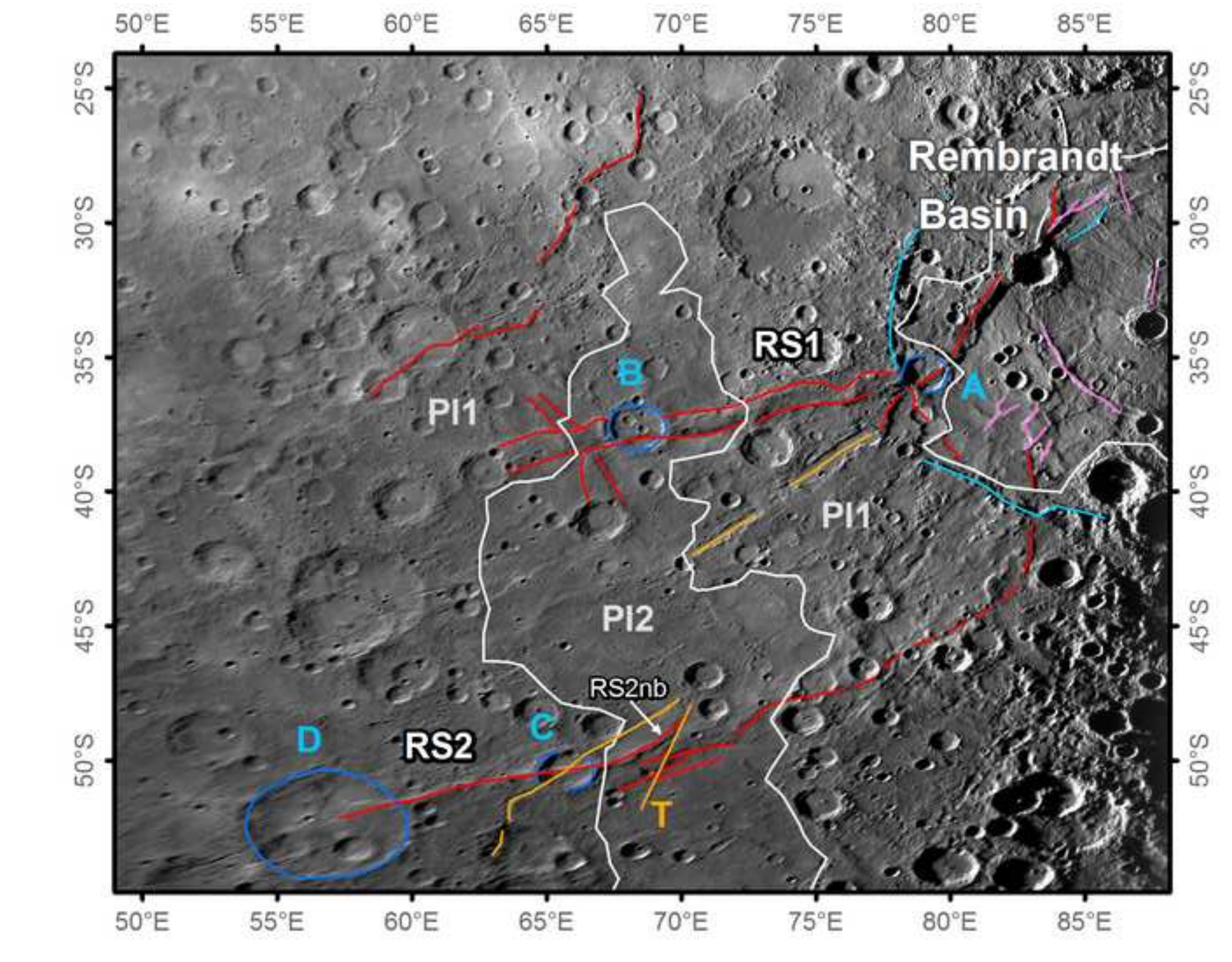
in

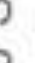

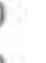
(1)

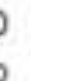
.

to downonad hich rocolution imamo 
Click here to download high resolution image

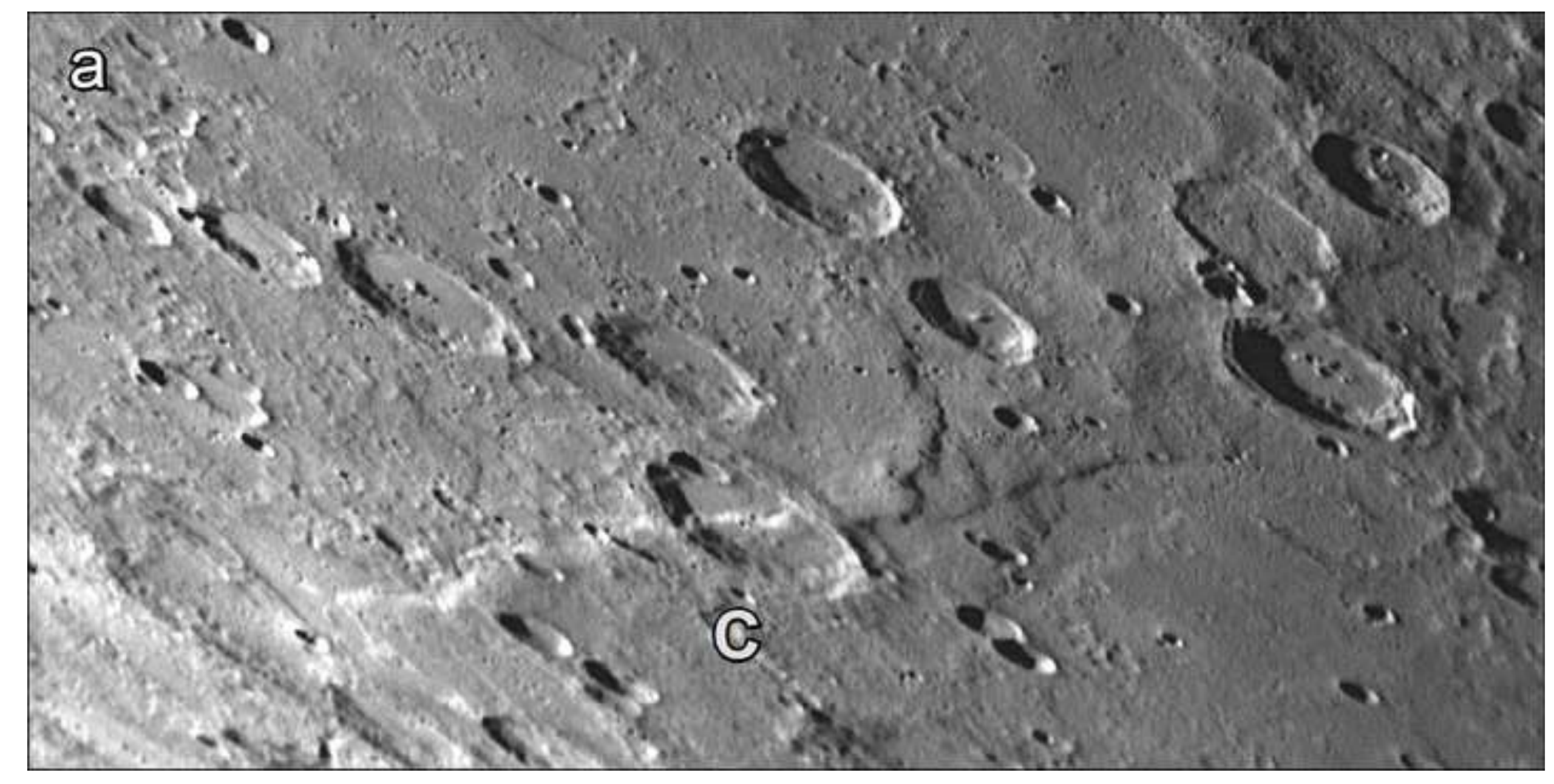


Click here to download high resolution image
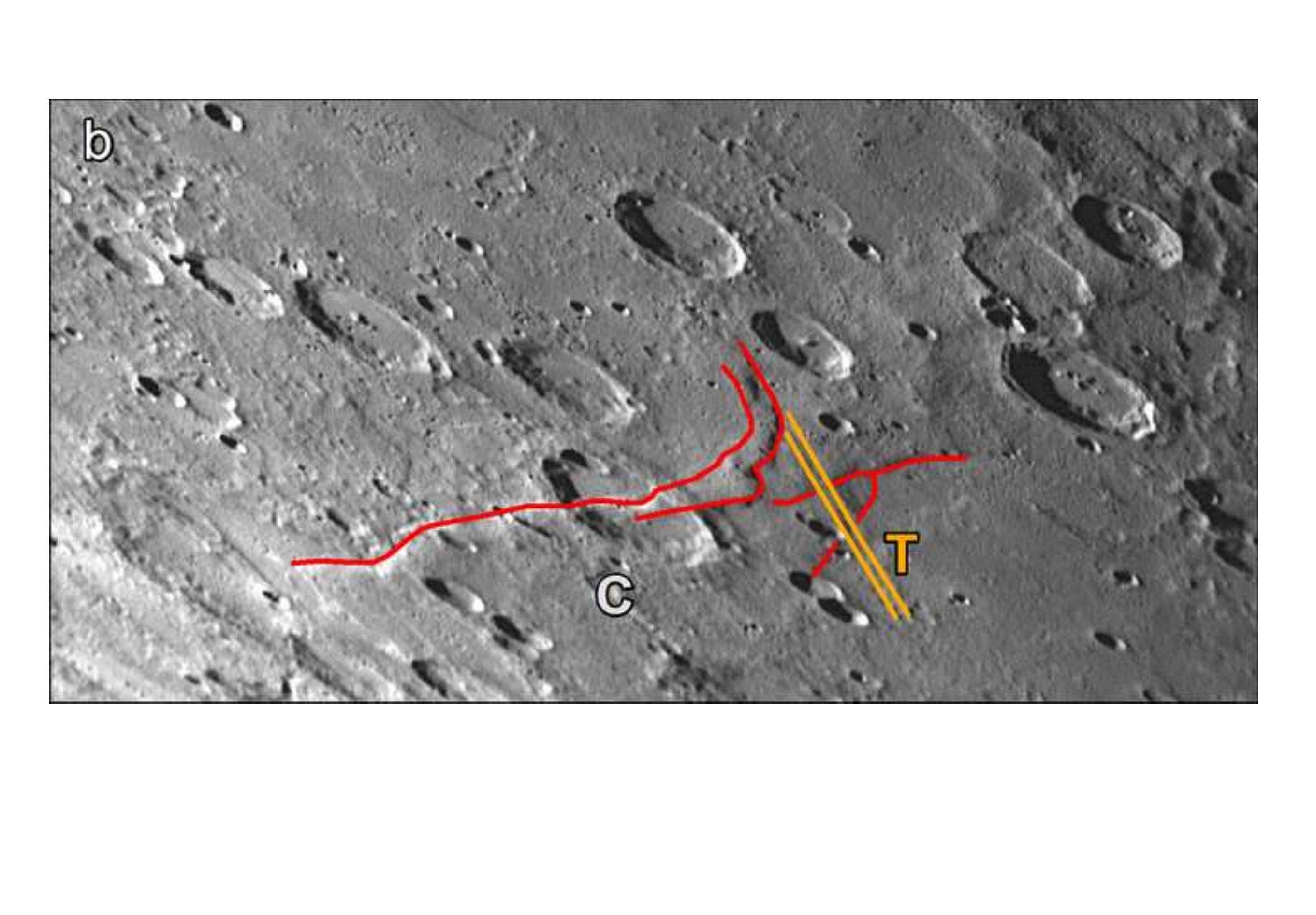

\author{
(
}

rats

.

.

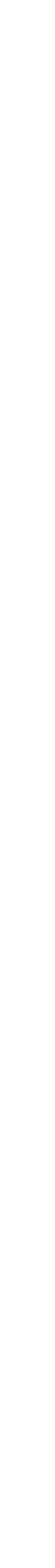

